\title{
Corrigendum: Bactericidal Property of Oregano Oil Against Multidrug-Resistant Clinical Isolates
}

\section{OPEN ACCESS}

Edited and reviewed by: Santi M. Mandal, Indian Institute of Technology

Kharagpur, India

*Correspondence:

Tianhong Dai

TDAl@mgh.harvard.edu

Mei X. Wu

MWU5@mgh.harvard.edu

Specialty section

This article was submitted to Antimicrobials, Resistance and

Chemotherapy,

a section of the journal

Frontiers in Microbiology

Received: 23 May 2021

Accepted: 14 June 2021

Published: 12 July 2021

Citation:

Lu M, Dai T, Murray CK and Wu MX (2021) Corrigendum: Bactericidal Property of Oregano Oil Against Multidrug-Resistant Clinical Isolates.

Front. Microbiol. 12:713573.

doi: 10.3389/fmicb.2021.713573

\author{
Min Lu ${ }^{1}$, Tianhong Dai ${ }^{1 *}$, Clinton K. Murray ${ }^{2}$ and Mei X. Wu ${ }^{1 *}$ \\ ${ }^{1}$ Wellman Center for Photomedicine, Massachusetts General Hospital, Harvard Medical School, Boston, MA, United States, \\ ${ }^{2}$ First Area Medical Laboratory, JBSA-Fort Sam Houston, Houston, TX, United States
}

Keywords: oregano oil, Pseudomonas aeruginosa, Acinetobacter baumannii, MRSA, biofilms, burn wound, mouse model, bioluminescence imaging

\section{A Corrigendum on}

Bactericidal Property of Oregano Oil Against Multidrug-Resistant Clinical Isolates by Lu, M., Dai, T., Murray, C. K., and Wu, M. X. (2018). Front. Microbiol. 9:2329. doi: $10.3389 /$ fmicb.2018.02329

In the original article, there was a mistake in Figure 4, panels $C$ and $D$ as published. The images from days 5 and 7 in Figures 4C and 4D are too similar and are not from two days apart (day 5 and day 7). The corrected Figure 4 appears below.

In the original article, there was a mistake in Figure 6, panels $C$ and $D$ as published. Figure 6C was mistakenly duplicated from Figure 6D. The matched images of Figures $6 \mathrm{E}$ and $\mathrm{F}$ from the same level of tissue slices as Figures 6C and 6D are updated accordingly. The corrected Figure 6 appears below.

The authors apologize for this error and state that this does not change the scientific conclusions of the article in any way. The original article has been updated.

Copyright $\odot 2021 \mathrm{Lu}$, Dai, Murray and Wu. This is an open-access article distributed under the terms of the Creative Commons Attribution License (CC BY). The use, distribution or reproduction in other forums is permitted, provided the original author(s) and the copyright owner(s) are credited and that the original publication in this journal is cited, in accordance with accepted academic practice. No use, distribution or reproduction is permitted which does not comply with these terms. 

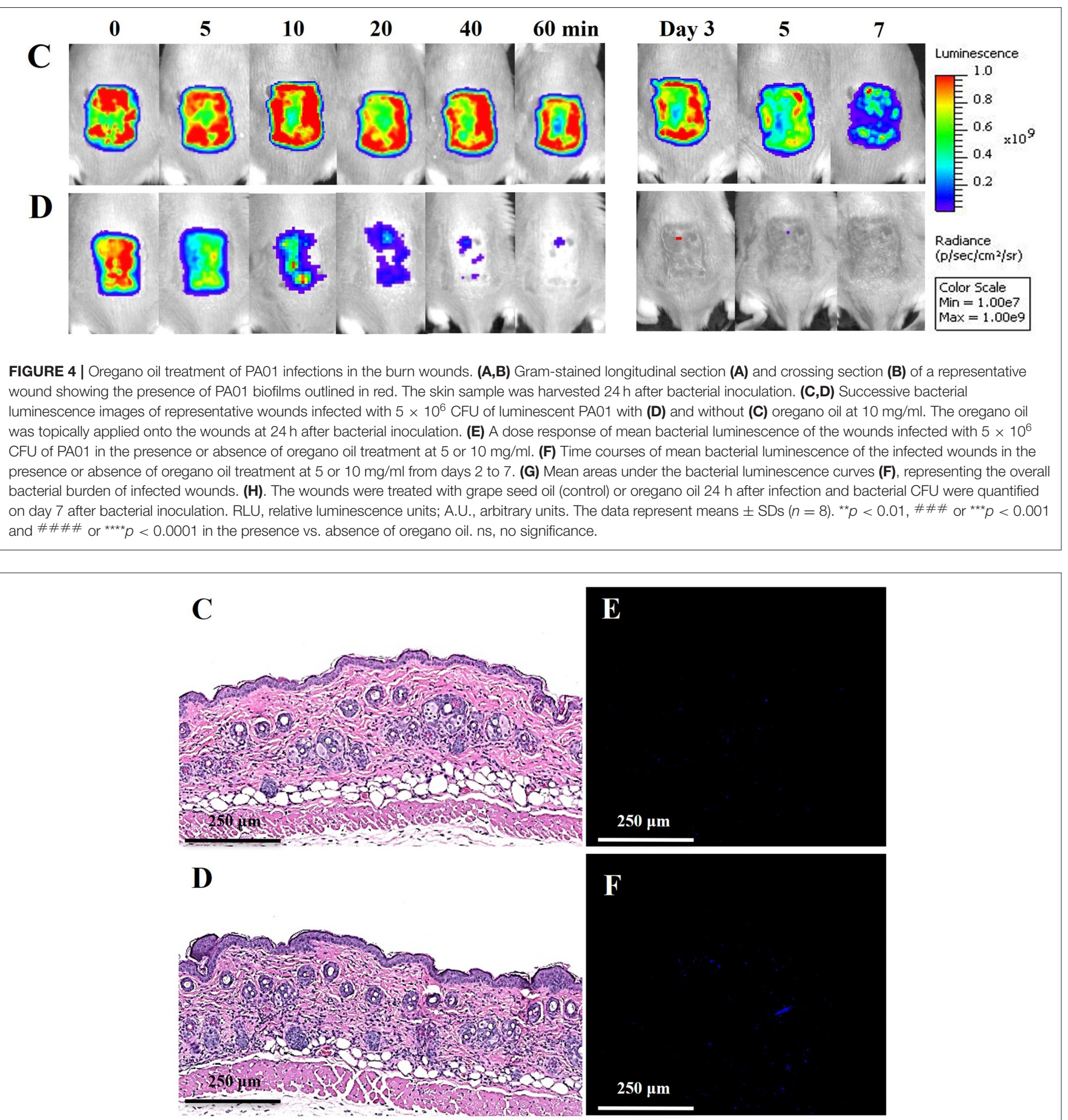

FIGURE 6 | Toxicity evaluation of oregano oil to normal mouse skins. The dorsal skin of mice was topically treated with (A,C,E) or without $10 \mathrm{mg} / \mathrm{ml}$ oregano oil (B,D,F) once a day for three consecutive days. On day 4, the skins were photographed (A,B), followed by histological examination (C,D). The skin sections were also TUNEL stained (E,F). DNase I treated skin samples (G) were TUNEL stained in parallel as positive-staining controls. 